\title{
A TIME STUDY OF THE PASTELLE MAKING PROCESS: AN INVESTIGATION AIMED AT REDUCING LABOUR AND TIME
}

\author{
Jeselle Gajadhar ${ }^{1}$, Aneil Ramkhalawan ${ }^{2 *}$ and Jorrel Bisnath ${ }^{3}$ \\ ${ }^{1,2,3}$ Design and Manufacturing Systems, The University of Trinidad and Tobago, Trinidad and \\ Tobago \\ ${ }^{1}$ Email: jesellegajadhar@gmail.com \\ ${ }^{2}$ Email: aneil.ramkhalawan@utt.edu.tt*(Corresponding author) \\ ${ }^{3}$ Email: jorrel.bisnath@utt.edu.tt
}

\begin{abstract}
Pastelles are a seasonal staple enjoyed primarily at Christmas time by Trinidadians. At present, pastelle production is limited to home cooks for personal consumption and/or low volume sales (output of 6 to 20 dozens based on demand) as well as established catering companies whose output goes up to the hundreds of dozens.

Regardless of the production scale, pastelle making has been a manual process involving long hours and laborious repetitive tasks to achieve the output. The ultimate goal is to design, build and test a prototype to assist pastelle producers with their output.

For this project, a time study of the processes involved was conducted by timing a few different pastelle makers to identify the average time taken for the various processes involved. From this study, it was determined that a powered press would assist the pastelle maker by reducing their effort and increase their consistency of the pressed dough. The mechanized pastelle press was created with a folding plate. User testing showed that the production time of pastelles increased, but there was a decrease in the energy input on pastelle makers. Hence, they could have made more pastelles by using the mechanism by reducing their energy input to manually press the dough. The folding plate also increased the folding time required to seal the pastelle. The results also showed that the production time reduced for two users, as their user time increased with the mechanized pastelle press. Hence, as their learning curve increased with the machine their production time reduced.
\end{abstract}

Keywords: pastelle, innovation, design, time study.

https://doi.org/10.47412/YXFH8312

\section{Introduction}

The process of making pastelles manually requires a significant input of time, effort and energy. Home cooks prepare the item for personal consumption or family gatherings at Christmas time. Well established caterers, as well as seasonal entrepreneurs also earn an income by making and selling pastelle [1]. In the catering business, chefs are always open to cutting down their preparation time for any item, to potentially expand their business via the ability to increase their supply to customers without sacrificing quality [2] [3]. 
A device was sought to increase the number of pastelles made within a predetermined period and/or decrease the effort needed, on the part of the maker to produce pastelles. The purpose of this machine would be to complete the actions of pressing the corn meal dough and folding the pastelles in a quick and easy manner, with minimal or less effort required from the user.

During the data collection and design process, it was determined that the device should have a footprint no larger than $1 \mathrm{~m} \times 0.5 \mathrm{~m}$ with a height of $1 \mathrm{~m}$ or less, be made of an affordable, food grade material and operates on 115VAC supply for use in residential kitchens. It should also be easy to disassemble and clean, reduce the pastelle assembly process in terms of time and effort. It should not require more than 1 person to lift, assemble and operate it.

\section{Methodology}

An assessment was conducted on existing technology for the pastelle making process. This determined what products were available on the market that also included devices created to make similar types of food. It would determine whether mechanizing the process would be economically viable and sustainable via sufficient consumer demand. Surveys were conducted with producers and consumers to determine buying habits and production targets.

Time studies were conducted with various pastelle producers using the current methods which would also determine the processes that were labour intensive via the effort required. This data would determine which part of the process was most time consuming and a design would be created and tested to reduce that time and effort. Interviews were then conducted with users of the prototype to determine user satisfaction.

\section{Literature Survey}

Research was conducted on the existing products available within the local market. The findings of which confirmed a need for a mechanized device designed specifically for making pastelles. Table 1 below shows some of the products that exist for pastelle making and provides a brief description of which processes the device assists with.

Although automatic turnover and pie machines do exist for similar procedures, these could not be used for cornmeal dough due to its stickiness and lack of elasticity as compared to flour dough. The devices that presently exist specifically for making pastelles are manual in nature thus requiring significant labour input to produce the items. The proposed machine would also need to be cost effective to be marketable.

Table 25: Advantages and disadvantages of existing products

\begin{tabular}{|c|c|c|}
\hline Product & Advantages & Disadvantages \\
\hline \multirow{6}{*}{$\begin{array}{c}\text { Manual Pastelle } \\
\text { Press }\end{array}$} & Does not require power supply & Labour intensive \\
\hline & Compact & Time consuming \\
\hline & Portable & Ergonomically unfriendly design \\
\hline & Fairly light weight & Useful only for pressing dough \\
\hline & Allows for individual wrapping of pastelles & Only process one item at a time \\
\hline & Cheap (\$22.00 - \$45.00USD) & [4] [5] \\
\hline $\begin{array}{l}\text { X-press Pastelle } \\
\text { Maker }\end{array}$ & Does not require power supply & $\begin{array}{l}\text { Does not allow for the use of fig } \\
\text { leaves for wrapping the pastelle }\end{array}$ \\
\hline
\end{tabular}




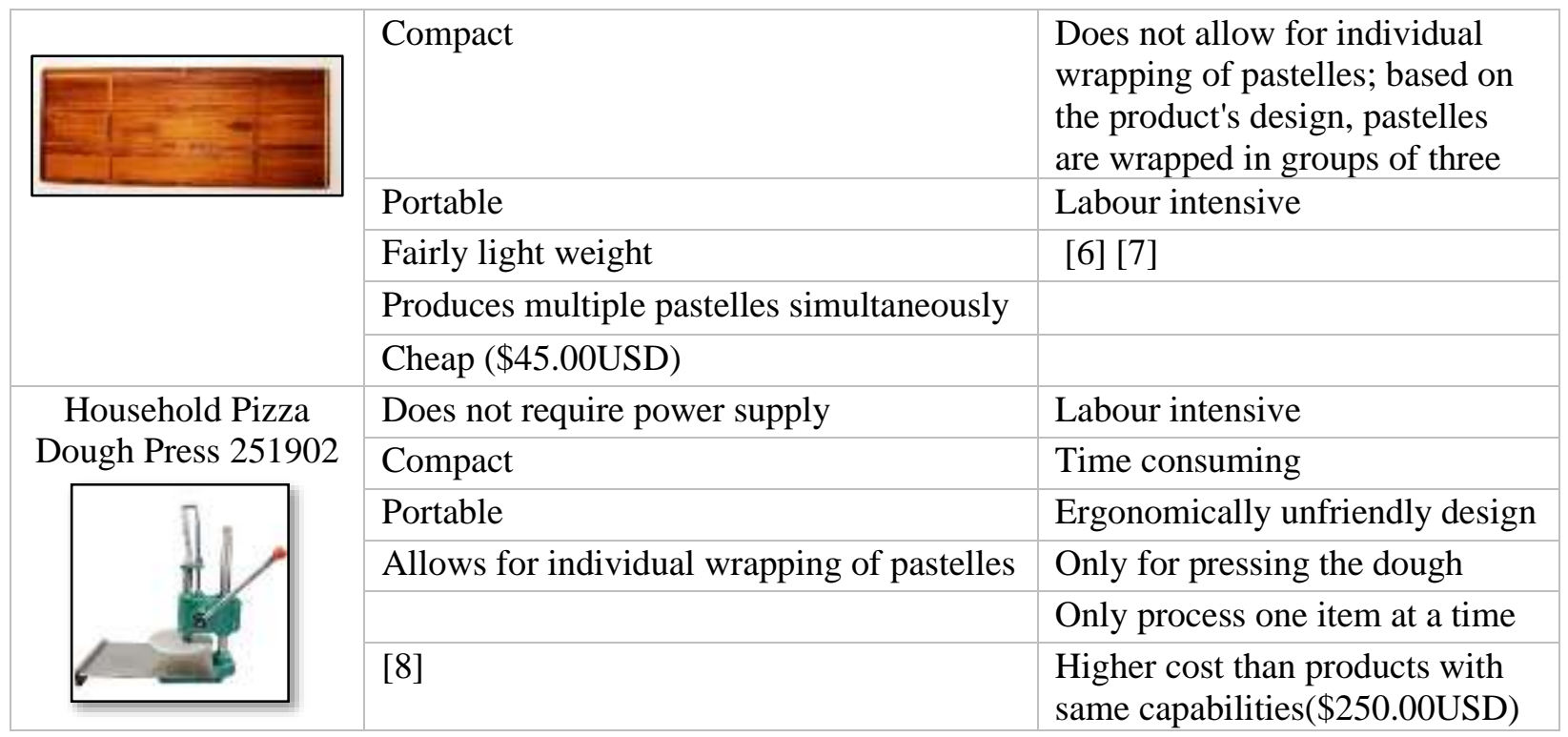

Patents were also reviewed; two were found which catered to the making of tortillas. US Patent No 4664025 A, 1987 consists of three tortilla making elements (lower, intermediate and upper) all connected via two vertical running spines, and resting on a base. The lower and upper elements have flat surfaces while the lower surface of the intermediate element is at an angle to the upper face of the lower element. The lower and intermediate elements are used for flattening the dough while the upper element's purpose is for cooking the flattened tortilla [9]. While US Patent No. 4938126 A, 1990, comprised of a non-stick, heat tolerant, conveyor belt moving at desired constant speeds to position tortilla dough balls between heated platens of a tortilla press. Two platens close to squeeze the dough balls between their faces while traveling in the same direction and at the same speed as the conveyor. The press is then opened (to dislodge the upper platen from the flattened dough), slowed, stopped and moved in the opposite direction of travel of the conveyor to a pre-determined start position. Once there, the press again begins to move at the same speed and in the same direction of the conveyor. The platens close on the another set of dough balls thus repeating the process [10].

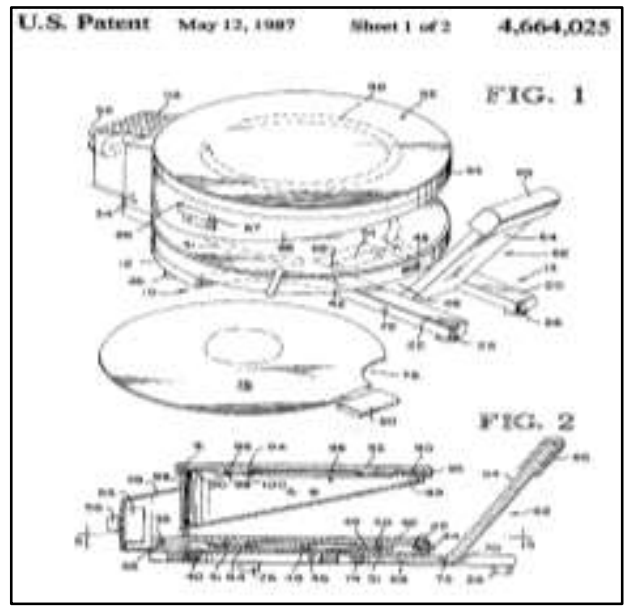

Figure 42: Patent 4664025 A

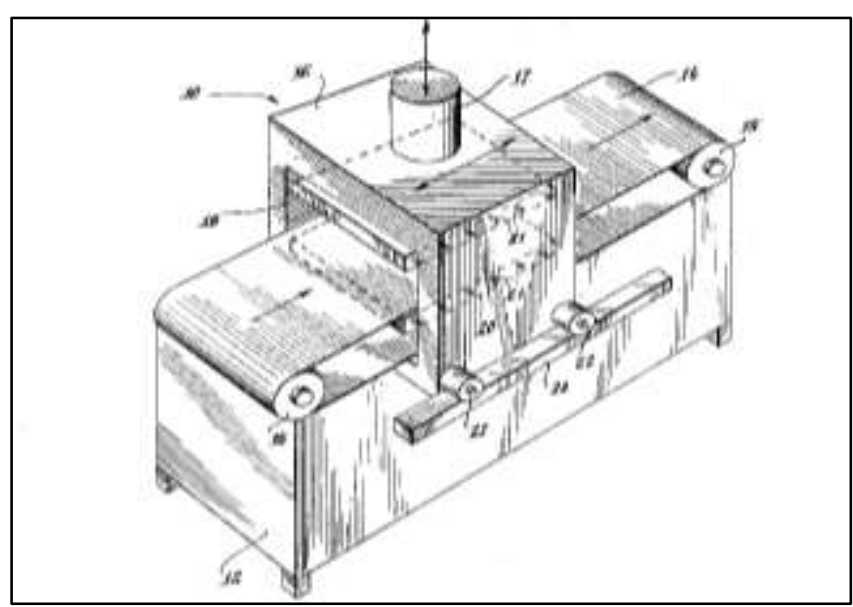

Figure 43: Patent 4938126 A respectively 


\section{Data Gathering}

Data was gathered by conducting time studies on the various processes involved in making pastelles and by also conducting interviews with the pastelle makers.

\subsection{Time Study 1 Results: Pastelle Making - Manual Process}

For this time study, data was collected on the force used to press pastelle dough, the setup and execution time for pressing the dough, and the execution time for folding the dough. The setup time refers to the time taken to remove the pressed dough from the fold plate, and place a new leaf and new dough shaped in a sphere to be pressed. Two candidates each were timed for pressing and folding the pastelles and the data was tabulated below in Table 2 . They were timed for approximately 7-8 pastelles and their averages were calculated as well as their maximum and minimum times for the various processes.

Table 26: Various Process stages data collected for both Candidates

\begin{tabular}{|c|l|c|c|c|}
\hline \multirow{2}{*}{ Data collected } & \multicolumn{3}{|c|}{ Time taken (s) } \\
\cline { 3 - 4 } & & \multicolumn{2}{|c|}{ Candidates } & Average between candidates \\
\cline { 3 - 4 } & Average & 51.48 & 19.92 & 35.7 \\
\hline \multirow{3}{*}{ Set-up time } & Maximum & 100.21 & 21.03 & 60.6 \\
\cline { 2 - 5 } & Minimum & 31.23 & 19.38 & 25.3 \\
\hline \multirow{3}{*}{ Press time } & Average & 15.94 & 15.63 & 15.8 \\
\cline { 2 - 5 } & Maximum & 20.11 & 21.82 & 21.0 \\
\cline { 2 - 5 } & Minimum & 8.81 & 10.14 & 9.5 \\
\hline \multirow{3}{*}{ Fold time } & Average & 25.94 & 74.97 & 50.5 \\
\cline { 2 - 5 } & Maximum & 50.07 & 205.41 & 127.7 \\
\cline { 2 - 5 } & Minimum & 1.34 & 20.33 & 10.8 \\
\hline Total Time for 6 Pastelles & 516.2 & 599.6 & 557.9 \\
\hline
\end{tabular}

Table 27: Summarized Data for Pressing the dough

\begin{tabular}{|c|l|c|c|}
\hline \multirow{2}{*}{ Data collected } & \multicolumn{2}{|c|}{ Force } \\
\cline { 3 - 4 } & Ag & $\mathrm{N}$ \\
\hline \multirow{3}{*}{ Pressing Force } & Average & 14.4 & 141.6 \\
\cline { 2 - 4 } & Maximum & 20.4 & 200.2 \\
\cline { 2 - 4 } & Minimum & 11.3 & 111.2 \\
\hline
\end{tabular}

Weights were used to calculate the force required for pressing the dough using 6 pastelles. Table 3 above gives the force calculated for pressing the dough. This would be used for designing the device.

\subsection{Design Requirements}

The time study and interviews conducted revealed that the press time and fold time stages were the most practical to try and assist in reducing the time taken. The interviews and observations also showed that most effort was required in the pressing stages due to the force required. This led to exhaustion depending on the 
number of pastelles that were required. It was therefore decided to design a device to assist in the pressing and folding stages of the pastelle making process. The following requirements were obtained through market surveys from the pastelles producers as well as from various standards.

Table 28: Design Specifications for Pastelle Maker

\begin{tabular}{|c|c|c|c|}
\hline Requirements & $\mathrm{D} / \mathrm{W}$ & Options & Source \\
\hline Material & $\mathrm{D}$ & Stainless Steel & Standard \\
\hline Geometry & $\mathrm{W}$ & $\begin{array}{l}\text { Not to exceed } 1 \mathrm{~m} \text { long, } 0.5 \mathrm{~m} \text { wide and } \\
0.5 \mathrm{~m} \text { high }\end{array}$ & Market Survey \\
\hline \multirow[b]{2}{*}{ Safety } & $\mathrm{D}$ & No loose parts once fully assembled & Standard \\
\hline & $\mathrm{D}$ & $\begin{array}{l}\text { Shield to be used at the pressing stage } \\
\text { to ensure user does not damage their } \\
\text { hand }\end{array}$ & Standard \\
\hline \multirow{2}{*}{ Ergonomics } & $\mathrm{W}$ & Easy to operate by one person & Standard \\
\hline & $\mathrm{W}$ & Pleasant appearance & Market Survey \\
\hline Operation & $\mathrm{D}$ & Powered by 115 VAC Supply & Standard [11] \\
\hline Cost & $\mathrm{W}$ & Must cost no more than $\$ 6000 \mathrm{TTD}$ & Market Survey \\
\hline \multirow[b]{2}{*}{ Maintenance } & $\mathrm{W}$ & Should require little to no maintenance & Standard \\
\hline & $\mathrm{W}$ & $\begin{array}{l}\text { Must be modular to allow for easy } \\
\text { disassembly and cleaning }\end{array}$ & Standard \\
\hline
\end{tabular}

D- Demand: which must be met / W- Wish: which can be met

\subsection{Alpha Prototype}

This prototype was developed using the design process. Various concepts were created from a morphological chart and the following design was chosen after conducting a design evaluation. For construction, the final design concept was broken down into individual components.

Mechanized Pressing Arm: This component comprised of a linear actuator fastened to two wooden plates. The linear actuator operates at 24VDC, had a stroke length of $0.150 \mathrm{~m}$ and a maximum weight capacity of $150 \mathrm{~kg}$. Each wooden plate was made from $0.254 \mathrm{~m} \times 0.128 \mathrm{~m} \times 0.015 \mathrm{~m}$ plywood and weighed $0.275 \mathrm{~kg}$. The downward face of the plate was laminated to allow easy cleaning of food particles during operation. The purpose of this component is to raise and lower the upper pressing plate that will flatten the pastelle dough onto the folding plate.

Arm Support: The arm support was constructed using two pieces of $0.076 \mathrm{~m} \times 0.019 \mathrm{~m}$ pitch pine wood, $0.648 \mathrm{~m}$ and $0.165 \mathrm{~m}$ lengths respectively, secured at a $90^{\circ}$ angle by two gypsum screws. This component secures the pressing arm to the base and suspends the upper pressing plate above the folding plate.

Folding Plate: The folding plate consisted of two $0.003 \mathrm{~m}$ thick aluminium sheets, vertically stacked and rivetted together using $0.002 \mathrm{~m}$ stainless steel rivets. The bottom sheet was $0.254 \mathrm{~m} \times 0.121 \mathrm{~m} \times 0.003 \mathrm{~m}$ and hinged along the $0.254 \mathrm{~m}$ side by a $0.152 \mathrm{~m}$, stainless steel 316 piano hinge with a $0.006 \mathrm{~m}$ spine. The top sheet was also $0.254 \mathrm{~m} \times 0.121 \mathrm{~m} \times 0.003 \mathrm{~m}$, with a $0.152 \mathrm{~m} \times 0.152 \mathrm{~m} \times 0.003 \mathrm{~m}$ cut-out made at the centre of the plate. For operation of the device, the user places their fig leaf and pastelle dough in the $0.003 \mathrm{~m}$ depressing on the plate for it to be flattened by the pressing arm.

Base: The base was a $0.254 \mathrm{~m} \times 0.257 \mathrm{~m} \times 0.114 \mathrm{~m}$ box constructed using $0.0127 \mathrm{~m}$ thick plywood and secured using gypsum screws. There was a $0.0127 \mathrm{~m}$ flange along the $0.254 \mathrm{~m}$ length of the box at an offset of $0.0064 \mathrm{~m}$ from the top edge, $0.0254 \mathrm{~m}$ in height. The base contained the maintained toggle switch for operation of the actuator on the press arm and housed the 24VDC Power supply. A $0.0254 \mathrm{~m} \times 0.0254 \mathrm{~m}$ 
cut-out was made on the back, right hand side of the base to accommodate incoming cable to the power supply.
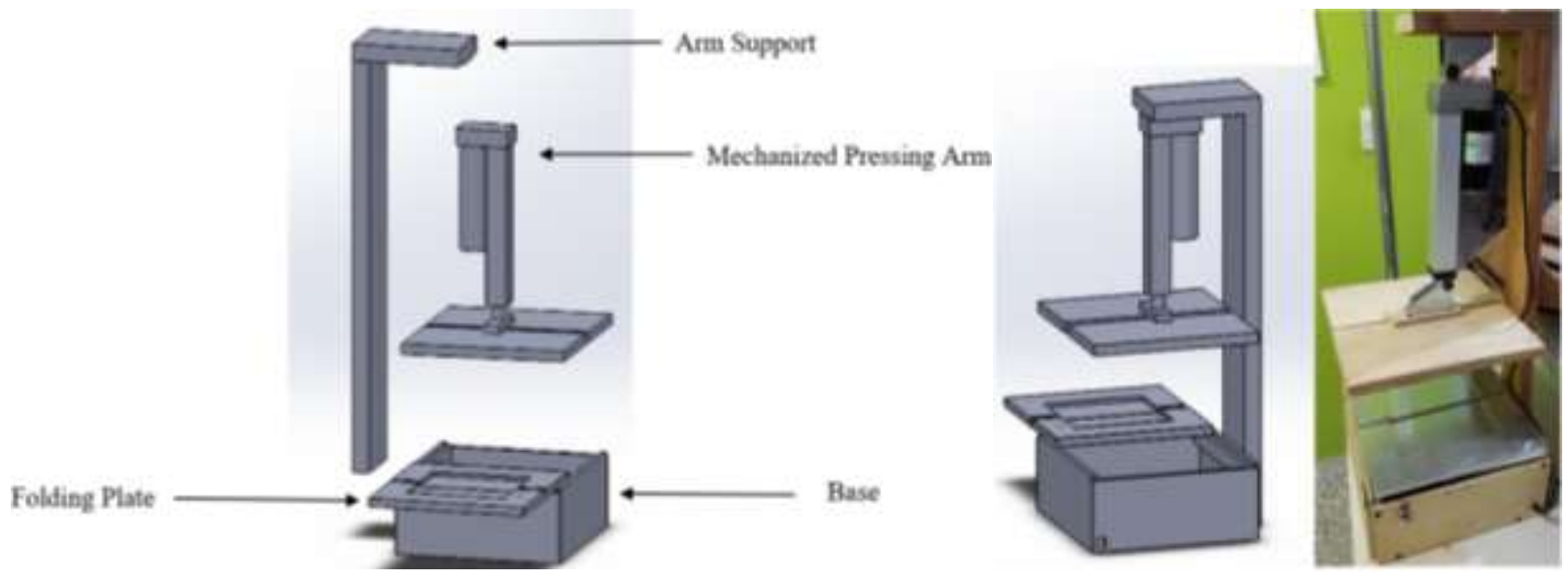

Figure 44: Constructed Alpha Prototype

\subsubsection{User Instructions for Operation of Prototype}

- Ensure toggle switch is in the center position

- Place folding plate on the base. Plate should be resting on the flanged edge of the base with the hinge perpendicular to the user.

- Plug the power cord into an electrical outlet.

- Place fig leaf on the fold plate.

- Place a $1 \mathrm{oz}$ ball of pastelle dough in the center of both the left and right-hand side of the folding plate depression.

- Place fig leave on top of the dough.

- Pull the toggle switch toward the user to allow the pressing arm to be lowered.

- Once the arm stops, push the toggle switch away from the user to raise the arm.

- Insert desired meat filling on the flattened dough on the right-hand side of the folding plate

- Slide the folding plate along the flange to the left and fold the left side of the plate onto the right.

- Fold the fig leaf to secure the pastelle and remove finished pastelle from the folding plate.

- Slide folding plate back to the right so that it is fully balanced on the base.

- Repeat from step 4.

\section{Results}

From the data collected in Time Study 1, the force used in the manual process for flattening the dough ranged from $142 \mathrm{~N}$ to $200 \mathrm{~N}$ (see Table 3 ). To find the force needed to flatten the dough into the prototype mould, the stress exerted on the dough via the manual process was calculated. Given the manual process flattens the dough into a circle and assuming a standard pastelle length of $0.152 \mathrm{~m}$,

radius of the flattened circle $\quad=0.152 \mathrm{~m} / 2$

$$
=0.076 \mathrm{~m}
$$

Driving force required on the actuator: $181 \mathrm{~N}<\mathrm{x}<255 \mathrm{~N}$

Based on the price and availability of actuators as well as the desired voltage and stroke length, the Z0600WH was selected [12]. 


$$
\text { Actuator Force }=1468.41 \mathrm{~N}
$$

Although the actuator force is six times higher than the maximum calculated force required, the depression in the press plate will ensure that the dough is flattened to a standard thickness of $0.003 \mathrm{~m}$.

Table 29: Data Collected for Time Study 2 Using the Prototype

\begin{tabular}{|c|l|c|c|c|c|c|c|}
\hline \multirow{2}{*}{ Data Collected } & \multicolumn{5}{c|}{ Candidates } & \multirow{2}{*}{$\begin{array}{c}\text { Av. Among } \\
\text { Candidates }\end{array}$} \\
\cline { 3 - 8 } & 1 & 2 & 3 & 4 & 5 & 30.6 \\
\hline \multirow{3}{*}{ Press Time } & Average & 32.2 & 30.8 & 32.2 & 29.0 & 29.0 & 35.4 \\
\cline { 2 - 8 } & Maximum & 43.1 & 31.0 & 42.4 & 29.8 & 30.5 & 28.9 \\
\cline { 2 - 8 } & Minimum & 28.5 & 30.2 & 29.9 & 28.0 & 28.0 & 61.0 \\
\hline \multirow{3}{*}{ Set-up Time } & Average & 60.5 & 114.5 & 41.0 & 39.0 & 50.2 & 70.3 \\
\cline { 2 - 8 } & Maximum & 69.8 & 129.0 & 46.9 & 45.7 & 60.1 & 42.7 \\
\cline { 2 - 8 } & Minimum & 41.1 & 100.1 & 28.1 & 20.1 & 24.1 & 14.2 \\
\hline \multirow{3}{*}{ Fold Time } & Average & 9.3 & 29.6 & 14.7 & 8.6 & 8.8 & 19.5 \\
\cline { 2 - 8 } & Maximum & 17.8 & 35.3 & 22.9 & 10.0 & 11.5 & 11.5 \\
\cline { 2 - 8 } & Minimum & 5.6 & 25.5 & 10.8 & 7.2 & 8.1 & 8.9 \\
\hline & Average & 6.9 & 20.9 & 8.8 & 3.7 & 4.2 & 16.0 \\
\cline { 2 - 8 } & Maximum & 11.0 & 37.7 & 22.1 & 4.5 & 4.6 & 5.8 \\
\cline { 2 - 8 } & Minimum & 4.4 & 13.9 & 4.1 & 3.1 & 3.7 & 688.64 \\
\hline \multicolumn{2}{|c|}{ Total Time for 6 Pastelles } & 653.64 & 1174.50 & 580.22 & 481.54 & 553.28 & \\
\hline
\end{tabular}

Table 30: Comparison of data before and after using Prototype

\begin{tabular}{|l|l|c|c|}
\hline Process stage & Criteria & Data collected before prototype & Data collected using prototype \\
\hline \multirow{3}{*}{ Press time } & average & 15.8 & 30.6 \\
\cline { 2 - 4 } & fastest & 9.5 & 28.0 \\
\cline { 2 - 4 } & slowest & 21.0 & 43.1 \\
\hline \multirow{3}{*}{ Fold Time } & average & 50.5 & 8.9 \\
& fastest & 10.8 & 3.1 \\
\cline { 2 - 4 } & slowest & 127.7 & 37.7 \\
\hline
\end{tabular}


Table 31: Comparison of data before and after using Prototype

\begin{tabular}{|c|c|c|}
\hline \multirow{2}{*}{ Criteria } & \multicolumn{2}{|c|}{ Time (s) to make 6 Pastelles } \\
\cline { 2 - 3 } & Before Prototype & After Prototype \\
\hline Fastest & 516.2 & 481.5 \\
\hline Slowest & 599.6 & 1174.8 \\
\hline Average & 557.9 & 688.64 \\
\hline
\end{tabular}

\section{Discussions}

From the data above, producing 6 pastelles using the protype took between 8 and 20 minutes. Extrapolating this data to a period of an hour, it is possible to produce between 18 to 45 pastelles within that time. Of the 5 candidates selected for testing of the prototype, two were repeats from the initial time study done on the manual process. These two candidates also had increased familiarity with the prototype due to their participation in user testing during preliminary stages of prototype development where the folding plate and pressing arm were tested as individual, independent pieces before being put together on the wooden frame to be tested as a complete unit. This familiarity allowed them to have faster times for the test than the other three. This indicated a learning curve for the candidates which leaves room for improvement on the slower test times with continued use of the device.

Looking at the time for the individual sections of the process, the average press time with the prototype is double that via the manual method. With the prototype however, the press time did have more consistent results than the manual method due to the fixed speed and force of the actuator as it raises and lowers. This allows for consistency in this section regardless of user fatigue. For folding however, the average time decreased by $80 \%$. One user reduced their average fold time from 25 seconds to 4 seconds while another with an average fold time of 75 seconds to 13 seconds.

\section{Conclusion}

Ultimately, although the device was able to reduce the time taken by users in folding pastelles, the average pressing time increased, but the consistency of the pressed dough was increased. However, the results also indicated that as the user gained more familiarity with the machine, their production reduced. Therefore, with more testing by the same users, this pressing time and hence production time can be reduced further. It could also be improved by changing the actuator to increase the time and also automating this part of the process. This resulted in minor differences in total time taken via the manual method verses the prototype for a target output of 6 pastelles. The device was however able to assist users by removing the physical output usually required for the pressing of the pastelles. 


\section{References}

[1] W. Rahamut, "The Pastelle Tradition," Guardian Media Limited, 23 November 2013. [Online]. Available: https://www.guardian.co.tt/article-6.2.411401.99ce45331e. [Accessed June 2018].

[2] R. Nuwer, "In Limited Supply, Trini Pastelles Are a Taste of Trinidad and Tobago," Edible Brooklyn, 7 December 2016. [Online]. Available: https://www.ediblebrooklyn.com/2016/trini-pastelles/. [Accessed June 2018].

[3] W. Rahamut, "The Joy of Pastelles," Newsday, 24 November 2018. [Online]. Available: https://newsday.co.tt/2018/11/24/the-joy-of-pastelles/. [Accessed February 2019].

[4] Felix, "Pastelle Press," Simply Trini Cooking, 15 March 2018. [Online]. Available: https://www.simplytrinicooking.com/pastelle-press/. [Accessed June 2018].

[5] F. Phillip, "Tools of the Trade," Caribbean Beat, September/October 2008. [Online]. Available: https://www.caribbean-beat.com/issue-93/tools-trade\#axzz6Ab37i0Op. [Accessed June 2018].

[6] Amazon.com, Inc, "INTERBUYING Household Pizza Dough Pastry Manual Press Machine Cough Presses(item\# 251902)," Techtongda, 2018. [Online]. Available: https://www.amazon.com/INTERBUYING-Household-Pastry-Machine-Presses/dp/B01N2G2T5X. [Accessed June 2018].

[7] X. P. Maker, "Xpress Pastelle Maker," Facebook, December 23 2014. [Online]. Available: https://www.facebook.com/xpresspastelles/. [Accessed June 2018].

[8] Vimeo, Inc, “The Next Best Pastelle Maker -(X-press Pastelle Maker AD)," Seon, 2016. [Online]. Available: https://vimeo.com/151270298. [Accessed June 2018].

[9] M. G. Martinez, “Tortilla Maker”. United States of America Patent 4664025, 29 July 1987.

[10] A. d. 1. V. E. M. L. Manuel J. Rubio, “Tortilla Press Apparatus”. United Stated of America Patent US4938126A, 9 May 1988.

[11] Trinidad \& Tobago Bureau of Standards, TTS 76: Part 13:2016- Requirements for labelling-Part 13: Labelling for Electrical Appliances, Trincity: Trinidad \& Tobago Bureau of Standards, 2016.

[12] Amazon.com, Inc, "Heavy Duty Linear Actuator 6" Inch Stroke 330 Pound Max Lift DC 12v/24v Position Feedback - Weather Resistant.," Zoom Industrial, 2018. [Online]. Available: https://www.amazon.com/Zoom-Industrial-Actuator-Position-

Resistant/dp/B072F3KNRK?psc=1\&SubscriptionId=AKIAINXEYUO4BHPXRRZQ\&tag=sazsy$20 \&$ linkCode $=x m 2 \&$ camp $=2025 \&$ creative $=165953 \&$ creative $A S I N=B 072 F 3 K N R K \& b t n=i m g l a r g e$ -d. [Accessed June 2018]. 